\title{
The impact of effective communication skills training on the status of marital burnout among married women
}

\author{
Alireza Jafari ${ }^{1}$, Ali Alami ${ }^{2}$, Elham Charoghchian ${ }^{3}$, Ali Delshad Noghabi ${ }^{1}$ and Mahbobeh Nejatian ${ }^{*}$ (i)
}

\begin{abstract}
Background: This study aimed to determine the impact of effective communication skills training intervention on the marital burnout among married women referring to health centers.

Methods: In this quasi-experimental study, 94 participants were selected from a descriptive study from among 936 married women referring to health centers who had a high rate of marital burnout and were randomly divided to the experimental group $(n=47)$ and control group $(n=47)$. The educational intervention was designed and performed in 7 sessions of $45 \mathrm{~min}$ for the experimental group. In the two stages before and after the intervention, the demographic sections, the Pines Marital Burnout Scale and effective communication skills were used to collect data. Data were analyzed using SPSS software version 24 and inferential test of Chi-square, Paired sample t-test and Wilcoxon test.

Results: There was no significant difference between the two groups before the intervention $(p>0.05)$. Performing the intervention in the experimental group significantly reduced the mean score of total marital burnout from 60.51 $( \pm 14.96)$ to 51.82 ( \pm 11.90$)$, and reduced the mean score of marital burnout subscales, including physical, mental and emotional burnout. Also, in this study, the educational intervention of the experimental group significantly improved effective communication skills, and the mean score of effective communication skills increased from 85.12 ( \pm 15.86) to $97.95( \pm 14.53)(p<0.001)$.
\end{abstract}

Conclusion: Based on the positive impact of effective communication skills on reducing marital burnout, it is recommended that more attention should be paid to enhancing these skills in spouses and pre-marital programs.

Keywords: Marital boredom, Effective communication skills, Education, Intervention, Couple burnout

\section{Background}

The history of marriage can be traced back to the beginning of history. Throughout history, marriage has been one of the most exciting and stressful events in everyone's life $[1,2]$. The formation of a healthy marriage is one of the factors for the successful establishment of a family, which will undoubtedly have a positive impact on society [3]. But as time passed, problems appeared in the

\footnotetext{
*Correspondence: m.nejatian1383@gmail.com

${ }^{1}$ Social Determinants of Health Research Center, Gonabad University

of Medical Sciences, Gonabad, Iran

Full list of author information is available at the end of the article
}

relationship between husband and wife, which reduced the love and affection between them and reduced life satisfaction [4]. One of the most important of these problems is marital burnout, which leads to emotional divorce and formal divorce among couples, and as a result, creates many problems for the couple's children and relatives $[5,6]$. Marital burnout is one of these psychological disorders. Over time, they will reduce the love and relationship between couples, cause psychological problems, and lead to emotional divorce and formal divorce [1]. Marital burnout is caused by a mismatch between the facts and expectations of the couple, and its severity depends on 
the compatibility of the couple and their beliefs. The first article on the marital burnout was published in scientific journal in the mid-1970s. Pines was the first to extend burnout to non-work areas and other aspects of life, and was the first to introduce marital burnout [7].

Marital burnout refers to a painful state of physical, emotional, and psychological exhaustion that occurs when couples realize that despite all their efforts, a relationship does not and will not give meaning to their lives [8]. The onset of burnout is rarely sudden and is usually gradual. Maslach and Jackson believe that marital burnout is divided into three stages, including physical, emotional, and psychological exhaustion [9]. Physical burnout are characterized by symptoms such as fatigue, lethargy, chronic headaches, abdominal pain, sleep disturbances, loss of appetite, and overeating. Emotional burnout refers to feelings of resentment, unwillingness to solve problems, frustration, sadness, feelings of emptiness, feelings of lack of motivation, being trapped, absurdity, emotional turmoil, and even suicidal motives. Psychological burnout refers to low self-esteem, negative attitude towards your spouse, feelings of despair and frustration with your spouse, and your own failure [10-13].

There are no statistics on the rate of marital burnout in Iran, but the rising number of divorces in this country, has led researchers to conduct educational interventions to prevent the causes of divorce in order to prevent the growing trend of divorce in Iran [10]. Therefore, various educational interventions on marital burnout have been performed in Iran $[3,11,14]$, but the special feature of this study is training using effective communication skills. The results of a systematic review study showed that interpersonal communication had a positive effect on marital satisfaction [15]. Communication skills are one of the best predictors of marital burnout. It seems that effective communication skills training can reduce the rate of marital burnout [16]. Couples who have effective communication skills express their desires more effectively, resolve their conflicts, share their thoughts and feelings more easily with each other, feel more intimacy and closeness to each other, and finally they experience a higher quality of marriage. A high quality of marriage helps couples to be less at risk of marital burnout $[17,18]$. The results of a study showed that couples who had more effective communication skills had significantly less marital boredom and were less likely to divorce [19].

In the effective communication training intervention, teaching and practicing the skills of sending and receiving messages, conflict resolution, practicing speaking skills, active listening skills, focusing on the problem, recognizing stress, confirmation of differences, requesting feedback, appreciation, and responsibility [20]. The rate of marital burnout in women was reported higher than men $[3,21]$. Studies have shown that the marital burnout has devastating effects and may lead to cause similar disorders in the children of these women [3, 21]. Also, women are more prone to stress due to the multiplicity of tasks they have, such as the upbringing of children, working at home, working outside the home, and as a result, they are more prone to marital burnout [22-24]. Therefore, women were considered as the study population and the present study was conducted to determine the effect of effective communication skills training intervention on the rate of marital burnout among married women referring to health centers.

The study's hypotheses were:

Hypothesis 1 The experimental group and the control group have significant differences in marital burnout, and its dimensions include physical burnout, emotional burnout and psychological burnout.

Hypothesis 2 In terms of effective communication skills, there are significant differences between the experimental group and the control group.

\section{Methods}

This study consisted of a descriptive study and a quasiexperimental study. A descriptive study was conducted to determine the marital burnout status of 936 married women at the Gonabad Health Center in Iran [25]. In the second stage, a quasi-experimental study was conducted on women with high rates of marital burnout to determine the impact of effective communication skills training on marital burnout among married women in Gonabad, Iran in 2020.

\section{Inclusion and exclusion criteria}

The inclusion criteria were: willing to participate in the study, filling out a written consent form, a resident of Gonabad, between the ages of 20 and 60, living with her husband and not suffering from mental illness. Exclusion criteria include: unwillingness to continue cooperation during the intervention program, absent more than one session in the training course, and divorce during the intervention program.

\section{Sample size}

Based on the previous study [26] and considering the loss rate of $10 \%$, the sample size of the intervention stage was calculated to be 94 participants (Experimental group $=47$, Control group $=47$ ). 


\section{Sampling method}

To select samples, 94 participants were selected from a descriptive study from among 936 married women referring to health centers who had a high rate of marital burnout and were randomly divided to the experimental group $(n=47)$ and control group $(n=47)$ (Fig. 1). The samples were randomly allocated to the control group and the experimental group by using NCSS PASS V.11 software.

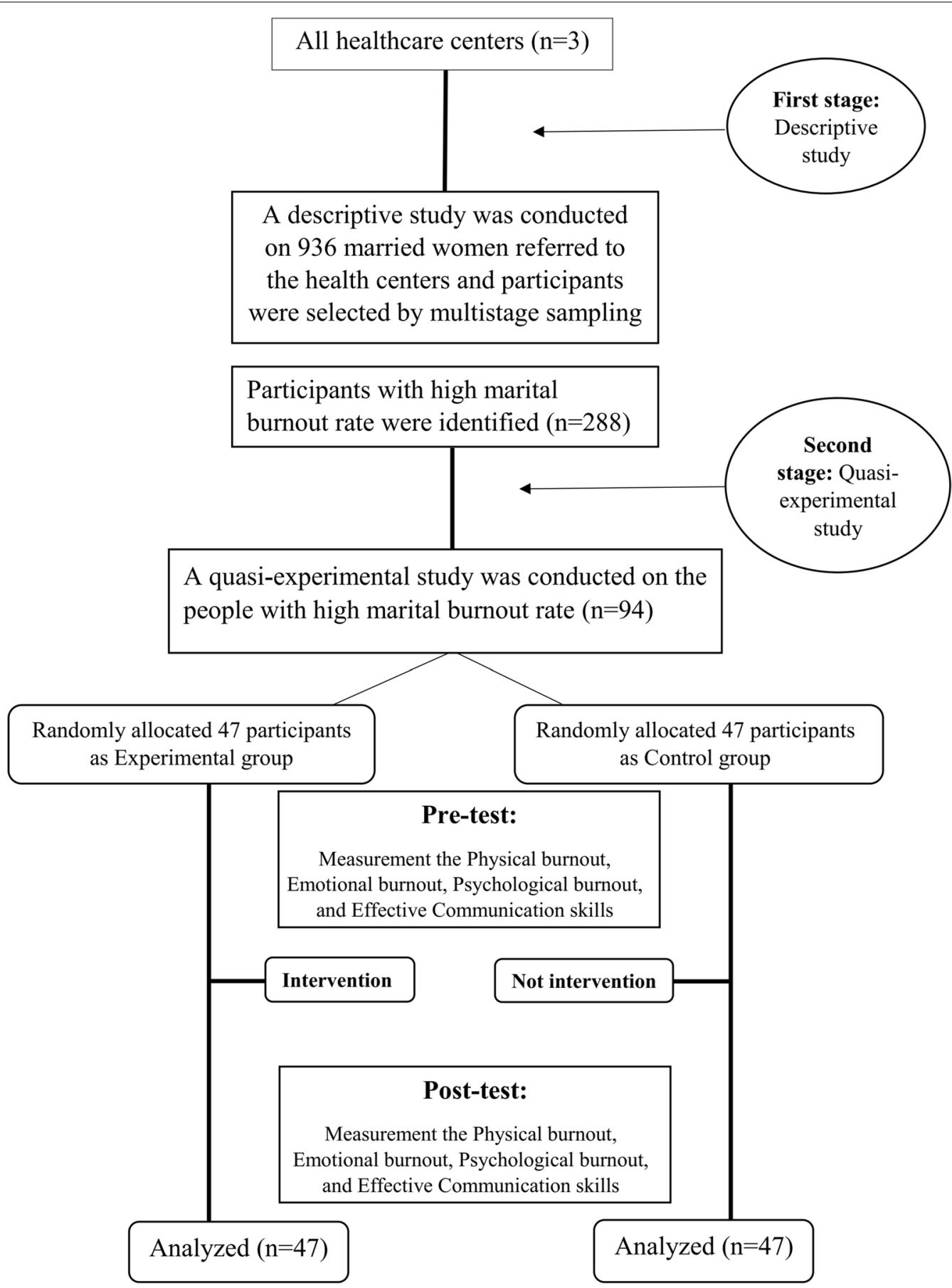

Fig. 1 The flow of participants through each stage of the study 


\section{Ethical considerations}

The research process began with obtaining the code of the ethics (IR.GMU.REC.1394.38) and registering in the clinical trial system (IRCT20180722040559N2). First, the objectives of the study were explained to the subjects and after obtaining informed consent from participants, questionnaires were given to them and was completed by self-report. The right to leave the study was reserved for those who did not wish to cooperate. Individuals are also assured that their information will be kept confidential from the research team.

\section{Data collection tools}

In this study, three questionnaires were used for data collection, including the demographic section, the marital burnout questionnaire and the effective communication skills questionnaire.

\section{The demographic questionnaire}

This questionnaire included questions such as age, education level, occupation status, husband's education, husband's occupation, length of marriage, number children, marital satisfaction and etc. (Additional File 1).

\section{Burnout measure (BM) scale}

To measure the marital burnout of married women, the Pains BM Scale has been used [8]. This scale includes 21 questions and three subscales of Emotional burnout (feeling depressed, being emotionally exhausted, feeling hopeless, feeling anxious, feeling burned out, being troubled, and feeling worthless), Physical burnout (being tired, being physically exhausted, feeling energetic, being wiped out, being weary, feeling rundown, and feeling weak), and Psychological burnout (having a good day, feeling trapped, being happy, feeling disillusioned and resentful about people, feeling unhappy, feeling rejected, and feeling optimistic). Each subscale consists of 7 questions that are measured on a 7-point Likert scale (never, once in a long time, rarely, sometimes, usually, often, always) and in each subscale, the lowest score is 7 and the highest score is 49 . The total marital burnout rate is based on the total score of each subscale. The lowest score is 21 and the highest score is $147[8,27]$. In this study, the lower mean score indicates the lower degree of the couple burnout. The validity and reliability of this questionnaire in Iran have been examined and its Cronbach's alpha level has been reported to be 0.82 [28].

\section{Effective communication skills questionnaire}

This questionnaire was designed by Miller et al. and contains 25 questions about effective communication skills [29]. Questions were evaluated on a 6-point Likert scale (rarely $=1$ to always $=6$ ). Scoring some questions is the reverse. In this tool, the minimum score was 25 and the maximum score was 150 . On this scale, a higher mean score indicates an improvement in effective communication skills. The validity and reliability of this questionnaire were examined in the Tavakolizadeh study and the Cronbach's alpha level was equal to 0.720 [30]. In this study, Cronbach's alpha of the effective communication questionnaire was 0.827 .

\section{Educational intervention program}

In the present study, an educational intervention was designed and performed in 7 training sessions of $45 \mathrm{~min}$ for the experimental group. Details of each training session were provided in Table 1. The questionnaires used

Table 1 Plan for conduction of the intervention

\begin{tabular}{|c|c|c|}
\hline Sessions & Behavior change techniques & Intervention strategies \\
\hline Session 1 & Lecture, slides(PowerPoint) & $\begin{array}{l}\text { Introducing the participants and outlining the goals and objectives of the } \\
\text { training program } \\
\text { In this session, we defining effective communication skills and explained } \\
\text { the importance of this skills in marriage }\end{array}$ \\
\hline Session 2 & Group discussion and brainstorming, lecture, slides (PowerPoint) & $\begin{array}{l}\text { In this session, we discussed the concept of effective communication } \\
\text { skills, its importance and role in the marital relationship }\end{array}$ \\
\hline Session 3 & Group discussion and brainstorming, lecture, slides(PowerPoint) & $\begin{array}{l}\text { In this session, we discussed the main elements of communication skills } \\
\text { (verbal and non-verbal) }\end{array}$ \\
\hline Session 4 & Lecture, Group discussion, Pamphlets, slides(PowerPoint) & $\begin{array}{l}\text { In this session, we discussed the types of communication behavioral } \\
\text { styles ( passive, aggressive, passive-aggressive, and assertive) }\end{array}$ \\
\hline Session 5 & Group discussion and brainstorming, lecture, slides(PowerPoint) & $\begin{array}{l}\text { In this session, we discussed the active listening training, its necessity and } \\
\text { functions, a variety of effective methods for active listening }\end{array}$ \\
\hline Session 6 & Group discussion and brainstorming, lecture, slides(PowerPoint), & $\begin{array}{l}\text { In this session, we discussed the barriers to effective communication } \\
\text { (such as humiliation, blame, defensiveness) }\end{array}$ \\
\hline Session 7 & Lecture, Group discussion & $\begin{array}{l}\text { Summary of educational content, remove ambiguities and answer the } \\
\text { participants' questions }\end{array}$ \\
\hline
\end{tabular}


in this study were assessed before the intervention and immediately after the intervention.

\section{Data analysis}

After entering the data into SPSS software version 24, first, the normality of the data was checked by the Kolmogorov-Smirnov test. Paired sample t-test and Wilcoxon test were used to compare the mean/median difference of the subscales before and after the intervention. To compare the mean/median of the subscales between the two groups before and after the intervention, t-test and Mann-Whitney tests were used. In all tests, the significance level was considered as $p$ value less than 0.05 .

\section{Results}

In this study, the mean (standard deviation) age of participants was $36.39( \pm 10.95)$. The majority of women $(79.6 \%, \mathrm{n}=74)$ and their husbands $(68.1 \%, \mathrm{n}=64)$ had diploma and under diploma. Approximately $81 \%(\mathrm{n}=76)$ of women were housewives and most of their husbands
(61.7\%, $\mathrm{n}=58)$ were self-employed. Also, 8.5\% $(\mathrm{n}=8)$ of participants reported that they got married by family force. Other demographic information can be seen in Table 2.

The results of the chi-square and independent samples t-test showed that there was no significant difference in terms of demographic variables between the experimental and control groups before the intervention $(p>0.05)$ and the two groups were homogeneous at the beginning of the study (Table 2). Also, before the intervention, the mean/ median score of total marital burnout, subscales of physical burnout, emotional burnout, psychological burnout, and effective communication skills did not show a significant relationship between the experimental and control groups $(p>0.05)$ and two groups were homogeneous in terms of these variables (Table 3 ).

After the intervention program, the results of paired sample t-test showed that the mean score of total marital burnout was significantly difference between two groups. This means that the educational intervention program significantly reduced the rate of total marital burnout in

Table 2 Socio-demographic characteristics of participants in baseline

\begin{tabular}{|c|c|c|c|c|c|c|c|}
\hline \multirow[t]{2}{*}{ Variable } & & \multicolumn{2}{|c|}{$\begin{array}{l}\text { Experimental } \\
\text { group }\end{array}$} & \multicolumn{2}{|c|}{ Control group } & \multirow{2}{*}{$\begin{array}{l}\text { All } \\
\text { N (\%) }\end{array}$} & \multirow[t]{2}{*}{$p$ value } \\
\hline & & $\mathbf{N}$ & $\%$ & $\mathbf{N}$ & $\%$ & & \\
\hline \multirow[t]{2}{*}{ Education } & Diploma and under diploma & 39 & 84.8 & 35 & 74.5 & $74(79.6)$ & $0.304^{*}$ \\
\hline & Academic & 7 & 15.2 & 12 & 25.5 & $19(20.4)$ & \\
\hline \multirow[t]{2}{*}{ Husband's education } & Diploma and under diploma & 31 & 66 & 33 & 70.2 & $64(68.1)$ & $0.825^{*}$ \\
\hline & Academic & 16 & 34 & 14 & 29.8 & 30 (31.9) & \\
\hline \multirow[t]{2}{*}{ Occupation } & Housewife & 42 & 89.4 & 34 & 72.3 & $76(80.9)$ & $0.065^{*}$ \\
\hline & Employee & 5 & 10.6 & 13 & 27.7 & $18(19.1)$ & \\
\hline \multirow[t]{2}{*}{ Husband's occupation } & Employee & 19 & 40.4 & 17 & 36.2 & $36(38.3)$ & $0.832^{*}$ \\
\hline & Self-employee & 28 & 48.3 & 30 & 63.8 & $58(61.7)$ & \\
\hline \multirow[t]{2}{*}{ Meet the husband before the marriage } & Yes & 16 & 35.6 & 18 & 38.3 & $34(37)$ & $0.931^{*}$ \\
\hline & No & 29 & 64.4 & 29 & 61.7 & $58(63)$ & \\
\hline \multirow[t]{2}{*}{ Length of marriage } & $<20$ & 36 & 76.6 & 32 & 69.6 & $68(73.1)$ & $0.490^{*}$ \\
\hline & $>20$ & 11 & 23.4 & 14 & 30.4 & $25(26.9)$ & \\
\hline \multirow[t]{2}{*}{ Married by family force } & Yes & 4 & 8.5 & 4 & 8.5 & $8(8.5)$ & $0.990^{*}$ \\
\hline & No & 43 & 91.5 & 43 & 91.5 & $86(91.5)$ & \\
\hline \multirow[t]{2}{*}{ Your relationship with your spouse } & Relative & 20 & 42.6 & 16 & 34 & $36(38.3)$ & $0.525^{*}$ \\
\hline & Non-relative & 27 & 57.4 & 31 & 66 & $58(61.7)$ & \\
\hline \multirow{2}{*}{$\begin{array}{l}\text { Engage in effective communication train- } \\
\text { ing courses }\end{array}$} & Yes & 8 & 17 & 5 & 10.6 & $13(13.8)$ & $0.552^{*}$ \\
\hline & No & 39 & 83 & 42 & 89.4 & $81(86.2)$ & \\
\hline \multirow[t]{2}{*}{ Marital satisfaction } & Yes & 41 & 89.1 & 44 & 93.6 & 85 (91.4) & $0.486^{*}$ \\
\hline & No & 5 & 10.9 & 3 & 6.4 & $8(8.6)$ & \\
\hline \multirow[t]{3}{*}{ Number of children } & Does not have & 0 & 0 & 2 & 4.7 & $2(2.3)$ & $0.187^{*}$ \\
\hline & $1-2$ & 30 & 68.2 & 25 & 58.1 & $55(63.2)$ & \\
\hline & 3 and more & 14 & 31.8 & 16 & 37.2 & $30(34.5)$ & \\
\hline Age & Mean (SD) & 36.72 & 11.60 & 36.06 & 10.37 & 36.39 (10.95) & $0.772^{* *}$ \\
\hline
\end{tabular}

${ }^{*}$ Chi-square, ${ }^{* *}$ Independent Samples T-test 
Table 3 Comparison of the mean and the median of constructs of couple burnout and effective communication

\begin{tabular}{|c|c|c|c|c|c|c|c|c|}
\hline \multirow[t]{2}{*}{ Variable } & \multirow[t]{2}{*}{ Group } & \multicolumn{2}{|c|}{ Before intervention } & \multicolumn{2}{|c|}{ After intervention } & \multicolumn{2}{|c|}{$\begin{array}{l}95 \% \text { confidence } \\
\text { interval }\end{array}$} & \multirow[t]{2}{*}{$p$ value* } \\
\hline & & Mean/median & SD/IQR & Mean/median & SD/IQR & Lower & Upper & \\
\hline \multirow[t]{4}{*}{ Physical burnout } & Experimental & 21.51 & 6.20 & 17.85 & 4.75 & 2.495 & 4.823 & $<0.001$ \\
\hline & Control & 21.19 & 7.06 & 22.00 & 6.51 & -1.236 & -0.040 & 0.037 \\
\hline & $p$ value ${ }^{* *}$ & 0.817 & & 0.001 & & - & & \\
\hline & $(\mathrm{t})$ & 0.233 & & -3.382 & & & & \\
\hline \multirow[t]{4}{*}{ Emotional burnout } & Experimental & 19.27 & 6.17 & 16.00 & 4.72 & 2.309 & 4.244 & $<0.001$ \\
\hline & Control & 17.21 & 6.46 & 18.40 & 6.28 & -1.858 & -0.524 & 0.001 \\
\hline & $p$ value ${ }^{* *}$ & 0.117 & & 0.039 & & - & & \\
\hline & $(\mathrm{t})$ & 1.582 & & -2.096 & & & & \\
\hline \multirow[t]{4}{*}{ Total marital burnout } & Experimental & 60.51 & 14.96 & 51.82 & 11.90 & 6.343 & 11.017 & $<0.001$ \\
\hline & Control & 57.40 & 17.26 & 60.17 & 16.46 & -4.135 & -1.396 & $<0.001$ \\
\hline & $p$ value ${ }^{* *}$ & 0.354 & & 0.006 & & - & & \\
\hline & $(\mathrm{t})$ & 0.932 & & -2.814 & & & & \\
\hline \multirow[t]{4}{*}{ Effective communication skills } & Experimental & 85.12 & 15.86 & 97.95 & 14.53 & -15.766 & -9.893 & $<0.001$ \\
\hline & Control & 85.91 & 13.71 & 85.95 & 12.47 & -0.852 & 0.767 & 0.916 \\
\hline & $p$ value ${ }^{* *}$ & 0.797 & & $<0.001$ & & - & & \\
\hline & $(\mathrm{t})$ & -0.257 & & 4.296 & & & & \\
\hline \multirow[t]{4}{*}{ Psychological burnout } & Experimental & 18 & $7(16-23)$ & 17 & $6(15-21)$ & 0 & 0.031 & $0.001^{* * * *}$ \\
\hline & Control & 19 & $6(15-21)$ & 20 & $7(16-23)$ & 0 & 0.031 & $0.002^{* * * *}$ \\
\hline & $p$ value $e^{* * *}$ & 0.641 & & 0.053 & & - & & \\
\hline & $(Z)$ & -0.466 & & -1.933 & & & & \\
\hline
\end{tabular}

IQR: Interquartile range

*Paired Samples T-Test, **Independent Samples T-test, ${ }^{* * *}$ Mann-Whitney Test, ****Wilcoxon test

the experimental group $(p<0.001)$, while in the control group without any intervention, the rate of total marital burnout significantly increased $(p<0.001)$ (Table 3 ).

Based on the results of paired sample t-test, after the intervention program the mean score of the physical burnout subscale were difference between two groups. This means that the training program has significantly reduced the rate of physical burnout in the experimental group $(p<0.001)$ and in the control group who did not receive any training, the rate of physical burnout significantly increased $(p<0.05)$. The results of paired t-test after the intervention program showed that there was a significantly difference between two groups in term of emotional burnout subscale. This means that the training program significantly reduced the emotional burnout rate of the intervention group $(p<0.001)$, while in the control group that did not receive any intervention, the emotional burnout rate was significantly increased $(p<0.05)$ (Table 3).

In Table 3, after the intervention program the results of the Wilcoxon test showed that the median score of psychological burnout subscale were difference between two groups. This means that the educational intervention significantly reduced the rate of psychological burnout in the experimental group $(p<0.05)$, while in the control group without any intervention, the rate of psychological burnout significantly increased $(p<0.05)$ (Table 3). Based on the results of paired t-test, the mean score of effective communication skills after the intervention showed a significantly difference between two groups. This means that the rate of effective communication skills was significantly increased in the experimental group than control group $(p<0.001)$ (Table 3$)$.

\section{Discussion}

The results of this study showed that the mean/ median score of total marital burnout, subscales of physical burnout, emotional burnout, and psychological burnout decreased significantly in the experimental group compared to the control group. Also, the mean score of effective communication skills increased significantly in the intervention group compared to the control group.

The results of the this study showed that the mean score of total marital burnout after the intervention was significantly difference between two groups and the rate of total marital burnout was significantly decreased in experimental group. The results of Rajani's study showed that the implementation of cognitive-behavioral couple 
therapy in the experimental group significantly reduced conflict and marital burnout among couples [2]. A study conducted by Sirin with the aim of investigating the effect of family education programs on the marital burnout among married women showed that the implementation of this intervention program significantly reduced marital burnout among married women in the experimental group compared to the control group [31]. The results of Padash's study showed that educational intervention based on the couple therapy causes a significant reduction in marital burnout in the experimental group and also reduces the rate of divorce among married women [32]. The results of a study showed that solution-focused therapy intervention reduced the rate of marital burnout in the experimental group and improved their marital quality [33]. Implementing pre-marital or post-marital education programs has a positive effect on the quality of life and marital satisfaction of couples and reduces their marital burnout [34-36].

Based on the results of this study, after the intervention program there was a significant difference between two groups in term of the mean score of the physical burnout subscale and the rate of physical burnout reduced in the experimental group. The results of a study showed that training through concentrated group discussion significantly reduced the physical burnout of the experimental group of women whose husbands were not addicted [26]. The results of a similar study showed that the implementation of educational programs can significantly reduce the rate of physical burnout in women [37]. The results of a study showed that life skills training significantly reduced physical burnout of the experimental group [38]. A study conducted by Ahrari showed that communication skills training can significantly reduce marital conflicts and reduce physical burnout between couples with marital problems [39]. Marital conflicts and lack of a proper relationship between couples can led to various marital problems and reduce their quality of life. Over time these problems can lead to physical burnout, such as fatigue, boredom, headaches, etc. in couples [40].

In this study, after the intervention there was a significant difference in the mean score of the emotional burnout subscale between two groups and the mean score in the experimental group was significantly decreased compared to the control group. The results of an interventional study showed that the implementation of an educational intervention program significantly reduced women's emotional burnout in the experimental group [26]. Based on the results of an educational intervention study that was conducted to investigate the effect of emotional therapy on marital burnout, showed that the emotional burnout rate of women in the experimental group has been significantly reduced [37]. The results of a study, which was conducted to investigate the effect of emotionally-focused couple therapy, and showed that this intervention program significantly reduced the marital burnout in the experimental group compared to the control group [41]. The results of Allan's research showed that the implementation of emotion-focused couple therapy intervention reduces the effects of marital burnout and causes less harm to children [42]. Strengthening the emotional burnout among couples reduces their mental disorders, increases sexual satisfaction, marital adjustment, and ultimately increases the quality and marital satisfaction [43-45]. Having effective can establish a good emotional relationship between husband and wife, and prevent marital burnout and marital conflict $[18,39$, 46].

In the present study, after the intervention, there was a significant difference in the median score of psychological burnout subscale between two groups, and the median score in the experimental group was significantly decreased compared to the control group. Based on the results of a similar study, the implementation of educational programs significantly reduced psychological burnout in the experimental group [26]. A study conducted by Asgari also showed that the implementation of an emotional schema therapy training program among couples who were going to divorce can reduced their psychological burnout and total marital burnout [14]. The results of Dehghan study showed that life skills training can improve women's life satisfaction, mental health and reduce marital burnout [47]. The results of a study showed that life skills training significantly reduced psychological burnout in the experimental group compared to the control group [38]. A study that was conducted to investigate the effect of communication skills on reducing marital conflict showed that strengthening these skills significantly reduced conflict and psychological burnout in the experimental group [40]. There is a relationship between mental health and marital burnout and marital satisfaction. People with better mental health status have higher marital satisfaction and less marital burnout [48-50].

The results obtained in this study showed that the mean score of effective communication skills after the intervention was significantly improved in the experimental group compared to the control group. Based on the results of Sajadi study, which was conducted to investigate the effect of effective communication skills training intervention on marital burnout status, showed that this training program significantly reduced marital burnout in the experimental group, and having communication skills is one of the effective factors in preventing marital burnout [51]. A study conducted by Tavakolizadeh showed that implementing a communication skills 
training program for married women in the experimental group can significantly reduce their marital conflicts [30]. Another study found that communication skills training significantly increased marital satisfaction and reduced marital conflict in the experimental group and improved the quality of life of couples [52]. The results of a study, which was conducted with the aim of enriching communication skills on reducing marital burnout, showed that strengthening these skills significantly reduces marital burnout and all aspects of burnout in couples and increases their marital quality [53]. When couples resolving their marital problems and conflicts, unsatisfied couples are more likely than other couples to show negative communicative behaviors, and rarely show positive communicative behaviors [54]. Having effective communication skills is one of the factors that reduce marital conflict, reduce the marital burnout, and improve marital quality between couples. Therefore, it is necessary to strengthen effective communication skills in premarital education programs to increase the quality of marital life of couples [55-58]. Therefore, women who believe that they do not have good communication skills and cannot solve marital problems can strengthen these skills with their husbands.

\section{Practice implications}

Due to the positive impact of effective communication skills training in reducing marital burnout, these skills can be used as an important preventive factor in reducing marital problems. All couples are advised to participate in effective communication training courses with their spouses before getting married, so that they have less problems in their married life. Married couples are also encouraged to attend these classes if they do not have effective communication skills. To strengthen these skills, they can refer to psychologists and counselors who specialize in this field, or use the educational videos available in this field, or read related books in the field of communication skills. It is also necessary for counselors in premarital and family counseling programs to pay more attention to the positive role of effective communication and provide the necessary information to their clients in this regard.

\section{Strengths and limitations}

One of the limitations of the present study was the lack of study on men and the study was performed only on women. Another limitation of the study was that the information was completed as a self-report before and after the intervention, which may be accompanied by a percentage of error. One of the limitations of this study was the lack of the survey of family income due to the lack of response from participants to this question. One of the advantages of the present study was the selection of participants based on a descriptive study that was selected for the intervention section from among these individuals. It is recommended that similar intervention plans for men and women be carried out in future studies.

\section{Conclusion}

The results of the present study showed that the implementation of an effective communication skills training program can be effective in reducing total marital burnout and its aspects (subscales of physical, emotional and psychological burnout) in married women. Having effective communication skills makes it possible for women to resolve their marital conflicts instead of escaping from marital problems. Solving marital problems can reduce their marital burnout and improve their quality of life. Considering the positive impact of effective communication skills training on reducing marital burnout, it is recommended that counselors and psychologists pay more attention to enhancing these skills in premarital training programs and couple therapy courses. It is also recommended that effective communication skills be taught to student adolescents in schools, so that these people will have a higher quality of marriage in the future and ultimately have a higher quality of life.

\section{Supplementary Information}

The online version contains supplementary material available at https://doi. org/10.1186/s12905-021-01372-8.

Additional file 1. Demographic Characteristics Questionnaire.

\section{Acknowledgements}

The authors would like to express their deepest appreciation to the women who participated in this study, and staff in the Social Determinants of Health Research Center who assisted the authors to run this research project.

\section{Authors' contributions}

Authors MN, AJ, AA, AD and EC designed the study. MN, AJ, AA, AD and EC participated in the conception of the study. AA and AJ managed and conducted the statistical analyses and interpreted the data. MN, AA, AJ, AD and EC wrote the first draft and $M N$ and $A J$ revised it to make the final manuscript. All authors have approved the final manuscript. All authors read and approved the final manuscript.

Funding

No financial support was received for this study.

Availability of data and material

The data sets used and/or analyzed during the current study was available from the corresponding author on reasonable request.

\section{Declarations}

Ethics approval and consent to participate

This study is based on a research project approved by Gonabad University of medical sciences with code of ethics IR.GMU.REC.1394.38 and registration in the Iranian Registry of Clinical Trials (IRCT20180722040559N2). Before the 
study, the written informed consent obtained from all participants. Also, those that were not minors at the time or participation provided their own written consent. All procedures performed in this study were in accordance with the ethical standards of the institutional and/or national research committee and with the 1964 Helsinki declaration and its later amendments or comparable ethical standards. Written informed consent was obtained from all individual participants included in the study.

\section{Consent for publication}

Not applicable.

\section{Competing interests}

The authors have no conflicts of interest.

\section{Author details}

${ }^{1}$ Social Determinants of Health Research Center, Gonabad University of Medical Sciences, Gonabad, Iran. ${ }^{2}$ Department of Epidemiology and Bio-Statistics, School of Public Health, Social Determinants of Health Research Center, Gonabad University of Medical Sciences, Gonabad, Iran. ${ }^{3}$ Student Research Committee, Mashhad University of Medical Sciences, Mashhad, Iran.

Received: 20 January 2021 Accepted: 24 May 2021

Published online: 03 June 2021

\section{References}

1. Abbasi Asfajir AA, Ramezani $L$. The relationship between family function and marital satisfaction with marital disaffection of married teachers in Behshahr. Sociol Stud Youth. 2017:8(24):9-22.

2. Rajani AA, Azizi LS, Naeemi S, Amiri AA, Javidan M, Abad HDG, Hosseini K: The effect of cognitive behavioral couple therapy on reduction of marital conflicts and burnout of couples. Turk Online J Des Art CommunTOJDAC (Special Edition) 2016:1649-1655. https://doi.org/10.7456/1060a gse/046

3. Safipouriyan S, Ghadami A, Khakpour M, Sodani M, Mehrafarid M. The effect of group counseling using interpersonal therapy (IPT) in reducing marital boredom in female divorce applicants. J Nurs Educ. 2016:5(1):1-11.

4. An L, Liu C, Zhang N, Chen Z, Ren D, Yuan F, Yuan R, Bi Y, Ji L, Guo Z. GRIK3 RS490647 is a common genetic variant between personality and subjective well-being in Chinese han population. Emerg Sci J. 2019;3(2):78-87. https://doi.org/10.28991/esj-2019-01171.

5. Udechukwu NS. Social work intervention against illegal child adoption. SciMed J. 2019;1(1):1-11. https://doi.org/10.28991/scimedj-2019-0101-1.

6. Aubeeluck ND, Luximon-Ramma A. The burdens of family caregivers of schizophrenia in Mauritius. SciMed J. 2020;2(3):118-31. https://doi.org/10. 28991/scimedj-2020-0203-2.

7. Pines A. Couple burnout: Causes and cures. London: Routledge; 2013. https://doi.org/10.4324/9781315022291.

8. Pines A, Aronson E. Career burnout: causes and cures. New York: Free Press; 1988.

9. Maslach C, Jackson S, Leiter M: MBI: Maslach burnout inventory: CPP, incorporated Sunnyvale (CA). 1996.

10. Mohammadi SA, Mohammadian MG. Prediction of marital boredom based on mindfulness and comparing these variables in couples of employed group and household Group in Ilam City. Eur J Behav Sci. 2018;1(2):24-35. https://doi.org/10.33422/EJBS.2018.05.30.

11. Amidisimakani $R$, Najarpourian S, Samavi SA. The effectiveness of acceptance and commitment therapy (ACT) on boredom and marital commitment in married women. Res Clin Psychol Counsel. 2018;7(2):55-68. https://doi.org/10.22067/IJAP.V712.62485.

12. Nikoubakht N, Karimi U, Bahrami H. Couple burnout among fertilized and unfertilized women referred to Valieasr Reproductive Center, Tehran. Ira J Epidemiol. 2011;7(1):32-7.

13. Alsawalqa RO. Marriage burnout: when the emotions exhausted quietly quantitative research. Iran J Psychiatry Behav Sci. 2019;13(2):e68833. https://doi.org/10.5812/ijpbs.68833.

14. Asgari A, Goodarzi K. The effectiveness of emotional schema therapy on marital burnout on the brink of divorce. Middle Eastern J Disab Stud. 2018;8:55-55
15. Zaheri F, Dolatian M, Shariati M, Simbar M, Ebadi A, Azghadi SBH. Effective factors in marital satisfaction in perspective of Iranian women and men: a systematic review. Electron Phys. 2016;8(12):3369. https://doi.org/10. 19082/3369.

16. Homaei R. Investigation of relationship between relationship skills and its components with couple burnout in married employees in NIDC Ahvaz. Rooyesh-e-Ravanshenasi J (RRJ). 2018;7(1):111-34.

17. Lavner JA, Karney BR, Bradbury TN. Does couples' communication predict marital satisfaction, or does marital satisfaction predict communication? J Marriage Fam. 2016;78(3):680-94. https://doi.org/10.1111/jomf.12301.

18. Haris F, Kumar A. Marital satisfaction and communication skills among married couples. Indian J Soc Res. 2018;59(1):35-44.

19. Zare Baghbidi M, Etemadifard A. Determining the Mediating Role of Communication Skills in the Relationship between alexithymia and marital burnout of divorce client Couples in Yazd. Q Soc Psychol Res. 2020;10(38):135-50. https://doi.org/10.22034/SPR.2020.114700.

20. Moghtader L, Akbari B. The impact of education communication skills on emotional regulation, resilience and marital satisfaction of mothers of hearing-impaired children. J Birjand Univ Med Sci. 2019;26(3):249-58. https://doi.org/10.32592/jbirjandunivmedsci.2019.26.3.106.

21. Ghanbari S, Esmaili Z, Pourebrahim T, Kholghi $\mathrm{H}$. The role of marital boredom with the mediation of the quality of maternal care in anticipation of externalizing and internalizing problems of children. J Manag Syst. 2017:7(26):55-72.

22. Sumra MK, Schillaci MA. Stress and the multiple-role woman: Taking a closer look at the "Superwoman." PLoS ONE. 2015;10(3):e0120952. https:// doi.org/10.1371/journal.pone.0120952.

23. Glynn K, Maclean H, Forte T, Cohen M. The association between role overload and women's mental health. J Womens Health. 2009;18(2):217-23. https://doi.org/10.1089/jwh.2007.0783.

24. Capri B. Eş tükenmişliğini yordayan değișkenlerin incelenmesi (Yayımlanmamış doktora tezi). Mersin Üniversitesi, Sosyal Bilimler Enstitüsü, Mersin 2008. https://doi.org/10.16953/deusosbil.528570

25. Nejatian M, Alami A, Momeniyan V, Delshad Noghabi A, Jafari A. Investigating the status of marital burnout and related factors in married women referred to health centers. BMC Womens Health. 2021;21(1):25. https://doi.org/10.1186/s12905-021-01172-0.

26. Khadivi E, Namani E. Effectiveness ff short-term solution-focused group training in couple burnout among the spouses of people freed from addiction. Int J Med Res Health Sci. 2016;5(9):262-7.

27. Enzmann D, Schaufeli WB, Janssen P, Rozeman A. Dimensionality and validity of the burnout measure. J Occup Organ Psychol. 1998;71(4):33151. https://doi.org/10.1111/j.2044-8325.1998.tb00680.x.

28. Ahmadi M, Zahrakar K, Davarniya R, Rezaiee M. The effectiveness of brief self-regulation couple therapy on couple burnout in couples of Saveh city. Razi J Med Sci. 2016;22(139):64-75.

29. Miller S, Miller P, Nunnally EW, Wackman D. Talking and listening together: couple communication one. Minneap: Interpers Commun Progr. 1991. https://doi.org/10.2307/584266.

30. Tavakolizadeh J, Nejatian M, Soori A. The effectiveness of communication skills training on marital conflicts and its different aspects in women. Procedia Soc Behav Sci. 2015;171:214-21. https://doi.org/10.1016/j.sbspro. 2015.01.112.

31. Sirin HD, Deniz M. The effect of the family training program on married women's couple-burnout levels. Educ Sci Theory Pract. 2016;16(5):156385. https://doi.org/10.12738/estp.2016.5.2781.

32. Padash Z, Yousefi Z, Abedi MR, Torkan H. Effect of Gottman's couple therapy on divorce tendency and marital burnout in married women. Middle Eastern J Disab Stud. 2020;10:154.

33. Mirzavand A, Riahi M, Mirzavand A, Malekitabar M. Effectiveness of solution-focused therapy on married couples' burnout. Iran J Psychiatry Behav Sci. 2016;10(4):4983. https://doi.org/10.17795/ijpbs-4983.

34. Ghasemi F, Nia KA, Amiri H. Effect of emotion-oriented couple therapy and cognitive-behavioral couple therapy on marital burnout. A comparative study. Arch Pharm Pract. 2020;1:104.

35. Kebritchi A, Mohammadkhani S. The role of marital burnout and early maladaptive schemas in marital satisfaction between young couples. Int J Med Res Health Sci. 2016;5(12):239-46.

36. Sayadi M, Shahhosseini tazik S, Madani Y, Gholamali lavasani M. Effectiveness of Emotionally Focused Couple Therapy on Marital Commitment 
and Couple Burnout in Infertile Couples. J Educ Commun Health. 2017;4(3):26-37. https://doi.org/10.21859/jech.4.3.26.

37. Raghibi M, Sanatnama M. The effectiveness of emotionally focused couple therapy in reducing couples' marital burnout and women's body image. Commun Health J. 2019;13(1):21-32. https://doi.org/10.22123/ CHJ.2019.141088.1166.

38. Momeni K, Dehqan F, Alizadeh Z, Bigdeli R. The effectiveness of life skills training on reducing the components of marital burnout among women married to disabled veterans. Military Psychol. 2017;8(31):5-16.

39. Ahrari A, Miri MR, Ramezani AA, Dastjerdi R, Hosseini T. Efficacy of communication skills training in marital disturbance. J Res Health 2020;10(6):351-8. https://doi.org/10.32598/JRH.10.6.1547.2.

40. Mazhari M, Zahrakar K, Shakarami M, Davarniya R, Abdollah-Zadeh A. The effect of relationship enhancement program (REP) on reducing marital conflicts of dual- career couples. IJN. 2016;29(102):32-44. https://doi.org/ 10.29252/ijn.29.102.32.

41. Naghdi H, Hatami M, Kiamanesh A, Navabinejad S. Comparing the effectiveness of the emotionally-focused couple therapy and the problemcentered systems therapy of the family on marital burnout in spouses of recovering addicts. J Kermanshah Univ Med Sci. 2017:4:e69658. https:// doi.org/10.22110/jkums.v20i4.3293.

42. Allan R. The use of emotionally focused therapy with separated or divorced couples. Can J Couns Psychother. 2016;50(3s):62-79.

43. Masoumi SZ, Khani S, Kazemi F, Kalhori F, Ebrahimi R, Roshanaei G. Effect of marital relationship enrichment program on marital satisfaction, marital intimacy, and sexual satisfaction of infertile couples. Int J Fertil Steril. 2017;11(3):197-204. https://doi.org/10.2174/15734048176662101111 41202.

44. Pinto-Gouveia J, Galhardo A, Cunha M, Matos M. Protective emotional regulation processes towards adjustment in infertile patients. Hum Fertil. 2012;15(1):27-34. https://doi.org/10.3109/14647273.2011.654310

45. Soleimani AA, Najafi M, Ahmadi K, Javidi N, Hoseini Kamkar E, Mahboubi $M$. The effectiveness of emotionally focused couples therapy on sexual satisfaction and marital adjustment of infertile couples with marital conflicts. Int J Fertil Steril. 2015;9(3):393-402. https://doi.org/10.1080/00926 239208412852

46. Jalali N, Heydari H, Davoudi H, Al-e-Yasin SA. Comparison of effectiveness of emotion-focused couple therapy and Gottman's relationships enrichment program on women's fear of intimacy. Int J Behav Sci. 2018;12(2):76-83.

47. Dehghan F, Piri Kamrani M, Goli R, Rahmani H. The impact of life skills training on marital satisfaction, marital dissatisfaction and mental health of veteran's wife. Q J Women Soc. 2017;7(28):1-12.

48. Ahola K, Hakanen J, Perhoniemi R, Mutanen P. Relationship between burnout and depressive symptoms: a study using the person-centred approach. Burn Res. 2014;1 (1):29-37. https://doi.org/10.1016/j.burn.2014. 03.003.

49. Kalhor M, Olyaie N. Relationship between marital satisfaction and mental health of married women referring to health centers in Sanandaj, Iran in 2014. Global J Health Sci. 2017;9(1):19. https://doi.org/10.5539/gjhs.v9n1p 19

50. Koutsimani P, Montgomery A, Georganta K. The relationship between burnout, depression, and anxiety: a systematic review and meta-analysis. Front Psychol. 2019:10:284. https://doi.org/10.3389/fpsyg.2019.00284

51. Sajadi S, Roshan R. Effectiveness of communication skills on attitude toward love and marital burnout. Coun Res Dev. 2015;14(53):91-111.

52. Moeini B, Karimi-Shahanjarini A, Soltanian AR, Valipour-Matlabi Z. The effect of communication skills training on females referred to health centers in Bahar; applying the social support theory for increasing marital satisfaction among couples. J Educ Commun Health. 2016;3(3):9-16. https://doi.org/10.21859/jech-03032.

53. Mohammadi M, Salimi A, Zahrakar K, Davarniya R, Shakarami M. Investigating the performance of relationship enhancement program (REP) on reducing burnout in couples. J Nurs Edu. 2016;4(3):8-16. https://doi.org/ 10.21859/ijpn-04032.

54. Bradbury T, Karney B. Intimate relationships. 2nd ed. New York: Norton; 2013.

55. Alipour Z, Kazemi A, Kheirabadi G, Eslami A-A. Marital communication skills training to promote marital satisfaction and psychological health during pregnancy: a couple focused approach. Reprod Health. 2020;17(1):23. https://doi.org/10.1186/s12978-020-0877-4.

56. Amini $\mathrm{M}, \mathrm{Heydari} \mathrm{H}$. Effectiveness of relationships enrichment education on improvement of life quality and marital satisfaction in married female students. J Educ Community Health. 2016;3(2):23-31. https://doi.org/10. 21859/jech-03024.

57. Soltani Ramezan Zadeh M, Rasoulian M, Mohammadsadeghi $\mathrm{H}_{\text {, }}$ Ahmadzad-asl M, Nohesara S, Soraya S, Eftekhari N. The effect of communication skills training and conflict resolution tactics on marital satisfaction of married women in Kermanshah. J Iran Med Counc. 2020;3(2):79-88.

58. Farbod E, Ghamari M, Majd MA. Investigating the effect of communication skills training for married women on couples' intimacy and quality of life. SAGE Open. 2014:4(2):2158244014537085. https://doi.org/10.1177/ 2158244014537085.

\section{Publisher's Note}

Springer Nature remains neutral with regard to jurisdictional claims in published maps and institutional affiliations.
Ready to submit your research? Choose BMC and benefit from:

- fast, convenient online submission

- thorough peer review by experienced researchers in your field

- rapid publication on acceptance

- support for research data, including large and complex data types

- gold Open Access which fosters wider collaboration and increased citations

- maximum visibility for your research: over $100 \mathrm{M}$ website views per year

At BMC, research is always in progress.

Learn more biomedcentral.com/submissions 